\title{
An Empirical Study on the Evolvement of Demands of Professional Ability of Managerial Students in Vocational Colleges by Employing Units
}

\author{
Yaling Liu \\ Guangdong Nanhua Vocational College of Industry and \\ Commerce \\ Guangzhou, China 510507
}

\author{
Yuyi Zeng \\ Guangdong Nanhua Vocational College of Industry and \\ Commerce \\ Guangzhou, China 510507
}

\begin{abstract}
Based on the data of survey of management professional position requirements in 2011 and 2016, the author analyzes the requirement changes of employ ability of vocational students in vocational colleges. The research finds that the professional vocational qualifications of vocational students have always been the most important. The learning ability is the most important key capability. And the demand for knowledge and social adaptability is significantly increasing. However, the requirements of market operation awareness and quality consciousness are significantly reducing. The demands for communication skills have professional differences. However, the degree of attention to the qualification certificate did not decrease. And then, the author would put forward some suggestions. First, it should improve the breadth and depth of knowledge of higher vocational students. It would prepare for their sustainable development. The second part is to encourage more vocational students to participate in social practice activities. And it could enhance their professional skills, communication skills and social adaptability. Thirdly, the professional qualification certificate should be linked with the post industry standards. Then, it would play its role.
\end{abstract}

Keywords-vocational college students; professional ability; key ability; changes

\section{INTRODUCTION}

Since its entry into the 21 st century, higher education has thrived and trained a large number of highly skilled professionals for the modernization construction. However, under the law of market economy, on the one hand, the employers seek talent with eagerness. However, the employers put quality before quantity. On the other hand, the employment rate of higher vocational colleges is not high. And "employment difficulties" are increasingly noticed. As great populous country, if this issue can't be resolved, it will have an adverse impact on social stability (Hu Xueqin, Lu Wanjun, 2009). Vocational education undertakes the task of cultivating high-quality laborers and millions of specialized personnel. Therefore, the development of vocational education should become one of the focuses of education development in China for a long period of time (Wang Xiuyan, 2011).
"National Medium and Long-term Education Reform and Development Plan (2010-2020)" stresses the need to adhere to the ability and to strengthen capacity construction. We should make efforts to improve students' learning, practice, innovation and education. The students should learn knowledge and skills. And then, it would promote students to take the initiative to adapt to the society. It clearly highlighted the important position of ability. In 2011, the Central Committee of the Communist Party of China and the State Council pointed out in the "Decision on Deepening the Reform of the Education System and Promoting Qualityoriented Education" in an all-round way: "Vocational education should enable students to master the necessary cultural knowledge. At the same time, the students should master vocational skills. And then, they may adapt to the job changes". Once again, it shows the importance of training team professional ability.

According to literature study, the author finds that the requirements of employers on the quality of personnel training would be reflected in the overall quality of vocational students. Zhang Guohong (2006) divided professional quality into nine dimensions, including career awareness and professional ability. Liu Yaling (2011) accordingly makes fine tuning. The professional quality is divided into 10 dimensions, including basic knowledge, professional ability, etc. And then, it could fully meet the needs of employers. Liu Lanming (2011) argues that vocational accomplishment refers to more in-depth ability and quality requirement of an organization in terms of personal qualifications. He also believes that there are "skills first", "offside ability" and "simple employment" and "temporary employment"t. The basic vocational education is relatively the "marginal" occupational education. Li Tiren and Li Jia (2013) believe that quality is potential ability. And the ability is the external quality of performance. And then, what is the position of vocational ability in the professional quality? Professional ability includes professional competence and key competencies (Zhang Guohong, 2006). Zhang Ting, Zeng Lingze (2014) and Li Chunyan (2015) studied the status quo and predicament of key competencies. Liu Yaling (2016) made a general statistical analysis of the employers' demand for vocational skills. 
Therefore, on the basis of the previous studies, this paper further makes an empirical study on the specific requirements and changes in employers' professional competence of vocational college students. In the actual investigation, the author takes the professional post of administrative management (referred to "administration"), marketing (referred to marketing) and sports services and management (referred to sports) as an example to collect data from the employer. And then, we would obtain the law of requirement changes of professional competence and key ability of higher vocational students. According to this issue, the author would put forward effective training methods and strategies. It would meet the employer's job requirements for professional positions. Also, it could provide first-hand data with a reference value for education peers. It would make up for the lack of empirical research in this area.

\section{RESEARCH METHODS}

The respondents are the employers in Guangdong province.

The contents of the investigation include the employer's demand for the vocational qualifications of higher vocational students, such as the requirement of academic qualifications and the importance of working experience, basic knowledge and professional ability. Employing units provide professional skills and key competencies for vocational students. The professional knowledge includes basic skills, professional skills and professional qualifications. The key capability includes learning ability and social adaptability. The employers and personal information may include the nature of the unit, size, length of service, positions and so on.

\section{A. Research Methods and Tools}

1) Self-administered questionnaires: From April to May, October to November 2011 and from April to May 2012, relevant professional investigators went to the talent centers in Guangdong province to conduct a survey on recruiting units by means of a combination of random investigation and interception investigation. They have investigated the needs for the quality of professional personnel in management, marketing and sports. They recycled 284 copies of effective questionnaires, and the effective rate is $100 \%$.

2) Internet survey method: In February 2016, a questionnaire was released in the "Questionnaire Star". The author could invite friends through the team members, create WeChat link and other means, and invite three professional staff to submit the questionnaire through online questionnaire system in the questionnaire star. Excluding the samples outside Guangdong province, a total of 372 valid questionnaires are completed. And the effective rate is $96 \%$.

\section{B. Research Procedures}

To find the questionnaire designed by Liu Yaling (2011), the questionnaire design is based on the viewpoints of Zhang Guohong (2006). And the professional quality is divided into
10 dimensions to conduct the research. According to the research, we need to conduct the questionnaire design in questionnaire star. In February 2016, it conducted a network survey of the employers.

It should clear up the questionnaire data of occupational quality research group from 2011 to 2012 (to improve the talent training program for each profession and to investigate different professional positions), and select the data relevant to this study. For the convenience of research, the figures in April to May, October to November 2011 and April to May 2012 are collectively regarded as the data of 2011.

We should study on the employer's professional quality - occupational skills. According to the survey data from 2016 and 2011, we find that the changes in the employer's requirements on vocational skills of higher vocational students. And then, we should identify their commonalities and professional specialty. It could provide the basis for vocational colleges to cultivate the professional ability of students.

This article needs to verify the following two assumptions:

First, employers' demand for knowledge of higher vocational students further declined;

Second, the degree of attention paid by employers to vocational qualification certificates obtained by students in colleges and universities has declined.

This assumption is based on the fact that China's development and construction emphasize on the application of competence. And it emphasizes on the concept of "theories-sufficiency scale". The State Council has successively banned the accreditation of more than 200 vocational qualification certificates since June 2014.

\section{THE ANALYSIS OF RESPONDENTS}

\section{A. The Sample of Professional Positions}

In 2011, the field survey included 114 administrative posts, 91 marketing posts, 79 sports posts. The total was 284 . In 2016, the sample sizes of various professional posts obtained through online surveys were 159,111 and 102 . The total was 372. The sample size of professional posts is consistent with the number of professional posts in the community. It indicates that the sample has certain representation.

\section{B. The Surveyed Enterprises}

1) The surveyed unit and area: The survey data from 2011 and 2016 comes from various regions of Guangdong province. In 2011, the data in Guangzhou accounted for $28.6 \%$. The data in Qingyuan accounted for $12.0 \%$. The data in Shenzhen accounted for $7.0 \%$. The data in Zhongshan accounted for $6.7 \%$. The data in Foshan accounted for 5.6\%. This is related to the fact that the school where the investigator works has campuses in Qingyuan and Guangzhou respectively. And the proportion of Guangzhou 
and Qingyuan is large. In 2016, the data came from the network survey, including $49.7 \%$ from Guangzhou, $12.9 \%$ from Chaoshan, $6.2 \%$ from Foshan, $4.8 \%$ from Shenzhen and $4.0 \%$ from Dongguan. The network survey was mainly carried out by snowball method. The sample distribution was related to the investigator's personal relationship and social relationship.

2) The nature of the surveyed unit: The proportion of private enterprises and individual industrial and commercial households was the largest in the two surveys. And the proportion in 2011 and 2016 was $37.8 \%$ and $38.4 \%$ respectively. Second, the proportion of the collective unit and the stock cooperation, the joint cooperation, the limited liability company, the stock limited company respectively is $28.6 \%$ and $37.9 \%$. The government organs or institutions accounted for $8.8 \%$ and $9.1 \%$ respectively. The urban stateowned units accounted for $9.5 \%$ and $5.9 \%$ respectively. And foreign investment and investment in Hong Kong, Macao and Taiwan accounted for $13.8 \%$ and $6.2 \%$ respectively. This is consistent with the structure of employers in Guangdong province, indicating that the sample is representative.

3) The size of surveyed units: In 2011, the number of units with the largest sample was 50-200, accounting for $39.9 \%$; Second, the number of units was less than 50 people, accounting for $31.7 \%$. In 2016 , the proportion of units with less than 50 persons was the largest, accounting for $38.6 \%$. Second, the number of units was 50-200 persons, accounting for $32.6 \%$. It can be seen that the majority of the surveyed units are small and medium-sized enterprises, which is consistent with the size of units in society.

\section{The status of surveyed respondents}

1) The post of surveyed respondents: In 2011, the sample positions were mostly managers, accounting for $32.30 \%$. In 2016, the sample positions were mostly commissioner, accounting for $29.60 \%$. In 2016, the position of investigators was slightly lower, which is related to the younger sample in 2016.

2) The working years of surveyed respondents: The samples with 3-5 years of service in 2011 were the largest, accounting for $32.8 \%$; the second was $1-3$ years, accounting for $29.5 \%$. The length of service in 2016 was 1-3 years, accounting for $48.9 \%$. This was followed by three to five years, accounting for $16.4 \%$. Overall, the sample of the 2016 survey was younger, which was related to the way in which the data were collected in 2016.

\section{ANALYSIS ON THE SURVEY RESUlts}

\section{A. The Employer's Demand for the Professional Quality of Vocational Students}

TABLE I. COMPARATIVE ANALYSIS OF VARIOUS PROFESSIONAL QUALITIES OF High VocATIONAL STUDENTS BY EMPLOYING UNITS

\begin{tabular}{|l|l|l|l|l|l|}
\hline \multicolumn{1}{|c|}{ Professional quality } & \multicolumn{1}{|c|}{$\mathbf{2 0 1 1}$} & $\mathbf{2 0 1 1}$ valued rank & \multicolumn{1}{c|}{$\mathbf{2 0 1 6}$} & $\mathbf{2 0 1 6}$ valued rank & \multicolumn{1}{c|}{ p ratios } \\
\hline vocational ability & $69.00 \%$ & 1 & $69.10 \%$ & 1 & 0.971 \\
\hline professional ethics & $66.20 \%$ & 2 & $69.10 \%$ & 2 & 0.434 \\
\hline basic knowledge & $52.50 \%$ & 5 & $64.80 \%$ & 3 & 0.002 \\
\hline Professional communication skills & $59.00 \%$ & 4 & $59.00 \%$ & 4 & 0.970 \\
\hline work experience & $65.80 \%$ & 3 & $58.90 \%$ & 5 & 0.071 \\
\hline Occupational etiquette & $41.00 \%$ & 6 & $45.20 \%$ & 6 & 0.290 \\
\hline professional ideal & $24.80 \%$ & 10 & $43.50 \%$ & 7 & 0.000 \\
\hline occupational psychology & $38.80 \%$ & 7 & $40.60 \%$ & 8 & 0.653 \\
\hline innovation quality & $37.10 \%$ & 8 & $37.10 \%$ & 9 & 10 \\
\hline entrepreneurship & $29.90 \%$ & 9 & $21.50 \%$ & 0.990 \\
\hline others & $0.50 \%$ & 11 & $0.30 \%$ & 11 \\
\hline (the total of sample) & 284 & 372 & \\
\hline
\end{tabular}

It should set a multi-choice question for the quality of occupation. And then, we could understand that the employing units pay attention to the professional quality. Through the classification and analysis of the different vocational qualities and the data of vocational college students, this paper takes the important percentage of the occupational quality that the employer considers different parts as its importance. In "Table I", from 2011 to 2016 , vocational ability has always been in the first position in the professional quality, validating the scientific conclusion that vocational ability is the core position of professional quality.

In the following, we could make in-depth analysis on vocational qualities which is closely related with the professional ability. 


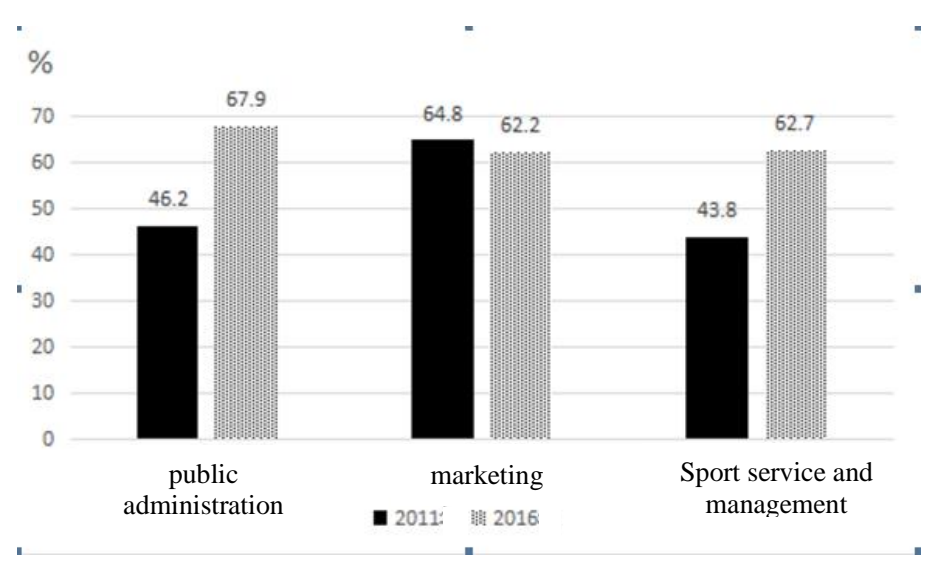

Fig. 1. Changes of emphasis on basic knowledge of vocational college students in each professional post.

1) Employers attach more importance to the basic knowledge of vocational college students: From "Fig. 1", it can be seen that there is a significant difference in the emphasis on the basic knowledge of vocational college students between 2011 and $2016(\mathrm{P}=0.014<0.05)$. And the emphasis on the basic knowledge of vocational college students would be more important in marketing and sports $(\mathrm{p} 1=0.001<0.005, \mathrm{p} 2=0.013<0.005)$. However, there is no significant change in the attention of marketing professional posts to the basic knowledge of higher vocational students $(\mathrm{P}=0.547>0.050)$, which has always been a relatively important state. It indicates that basic knowledge has become a necessary condition for post demand.

2) Marketing professional posts pay more attention to vocational ability of higher vocational students: There was no significant difference in the importance of vocational ability among different professional posts in $2011(\mathrm{P}=0$. $376>0.050)$. There was a significant difference between $63.7 \%-72.8 \%$ in $2016(\mathrm{P}=0.020<0.05)$. And the degree of significance is $59.8 \%-77.5 \%$. Among them, the professional ability of the students in marketing professional posts increased significantly $(\mathrm{P}=0.032<0.05)$, from $63.7 \%$ to $77.5 \%$. There was no significant change in professional posts and sports professional posts $(\mathrm{P}=0.516$ and 0.193 , respectively). However, the emphasis on vocational ability of vocational college students has always been in a high level.

The vocational ability in the professional quality is most valued by the employing unit. The vocational ability includes the professional ability and the key ability. Therefore, we would make special analysis on the professional ability and the key ability of the higher vocational students.

\section{B. Changes of the Employer's Opinion on the Professional Competence of Vocational Students}

For the professional ability, we set up a multi-topic. And we want to know which professional ability valued by the employers. Through the interactive analysis of the options and data of professional ability of vocational college students, we could extract the percentage that employer's think each professional ability is important. And it could be regarded as the importance of professional ability.

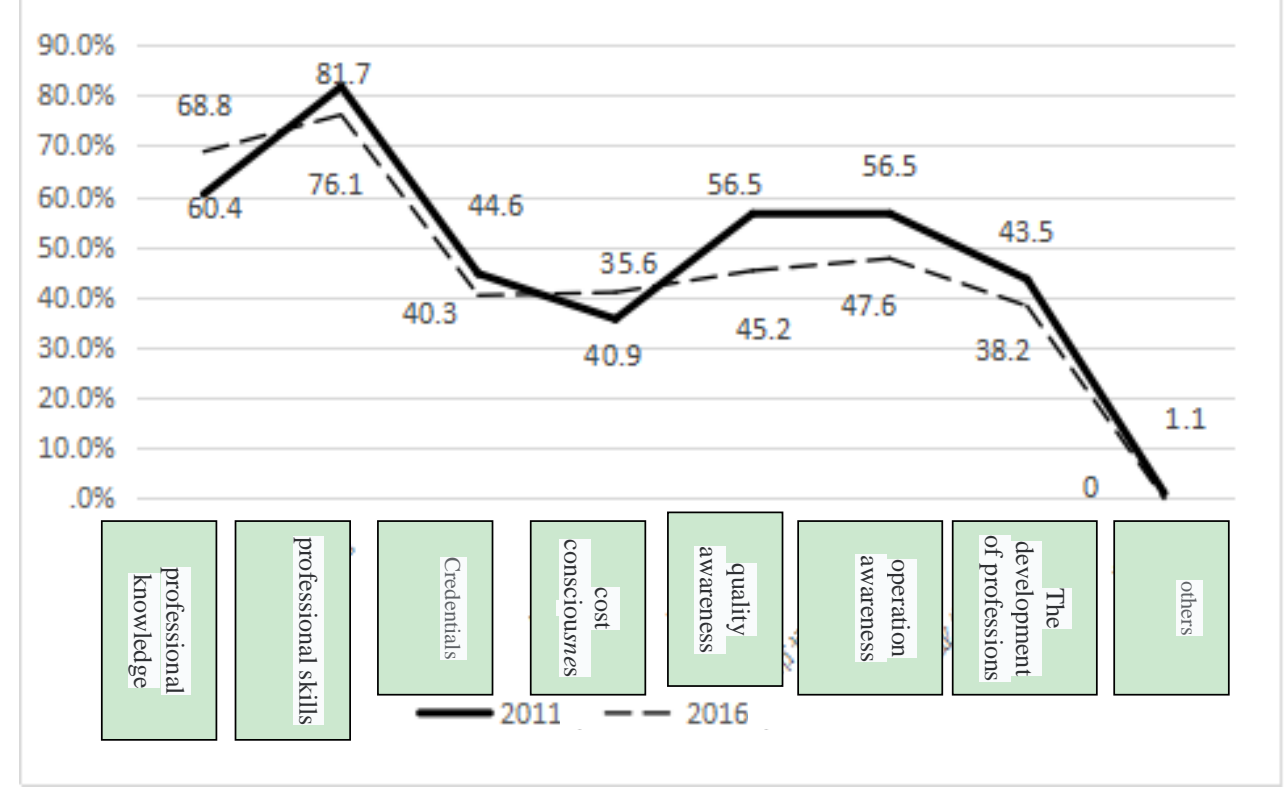


Fig. 2. Comparative Analysis of Employers' Perceptions on Professional Ability of Higher Vocational College Students.

As can be seen from "Fig. 2", the most valued professional competencies in 2011 were professional skills. And the second was professional knowledge. The third was quality awareness and market operation awareness. The fourth was qualification certificates. They respectively accounted for $81.7 \%, 60.4 \%, 56.5 \%, 56.5 \%$ and $44.6 \%$. By 2016, the importance of professional knowledge increased from $60.4 \%$ to $68.8 \%$. The importance of quality awareness and market operation awareness decreased from $56.5 \%$ and $56.5 \%$ to $45.2 \%$ and $47.6 \%$, respectively.

The changes in the importance of professional ability provide a reference to improve the personnel training program for us. In the following, we make a further analysis on the professional ability of the first four specialties.

1) Professional posts still attach great attention to vocational students' professional skills: The survey shows that the employers pay little attention to vocational students' professional skills ( $p>0.050$ ). When it comes to specialty, the emphasis of administration on professional skills decreased significantly $(\mathrm{p}=0.004<0.050)$, from $90.4 \%$ to $76.7 \%$, which was consistent with other specialty posts. There was no significant difference between professional marketing posts and professional sports posts in the importance of professional skills $(\mathrm{P}=0.807>0.050, \mathrm{P}=0$. $7>0.050$ ), which indicated that professional skills were still the most important professional ability for employers.

2) The increasing emphasis on the professional knowledge of the students in various professional posts: The data shows that the employers' attention to vocational students' professional knowledge increased significantly $(\mathrm{p}=0.026<0.05)$, from $60.4 \%$ to $66.8 \%$. The professional knowledge of vocational college students has been improved in various degrees. Therefore, higher vocational colleges should pay more attention to the training of professional knowledge.

According to further analysis ( $p=0.042<0.050)$ on the variables of major qualifications of employers in the future recruitment of qualified personnel and professional knowledge, the higher the education level is, the higher the degree of professional knowledge of higher vocational students will be.

To sum up, the employers greatly improve professional knowledge and academic qualifications. They emphasize on the basic knowledge. The assumption that "the employers further decline the demand for the knowledge of higher vocational students" is falsified.

3) The demand for quality awareness of higher vocational students is generally lower: Emphasis on quality consciousness was significantly reduced $(\mathrm{p}=0.004<0.05)$, from $56.5 \%$ to $45.2 \%$. As for the specialty, the quality consciousness was significantly reduced in the professional post $(\mathrm{p}=0.029<0.050$, from $58.9 \%$ to $42.2 \%$ ) and the professional post ( $\mathrm{p}=0.029<0.05$, from $64.0 \%$ to $43.4 \%$ ). There was no significant change in the quality consciousness of marketing professional posts $(\mathrm{P}=0.445$ > 0.050). It can be seen that most professional positions have a significant reduction in the quality consciousness of vocational students.

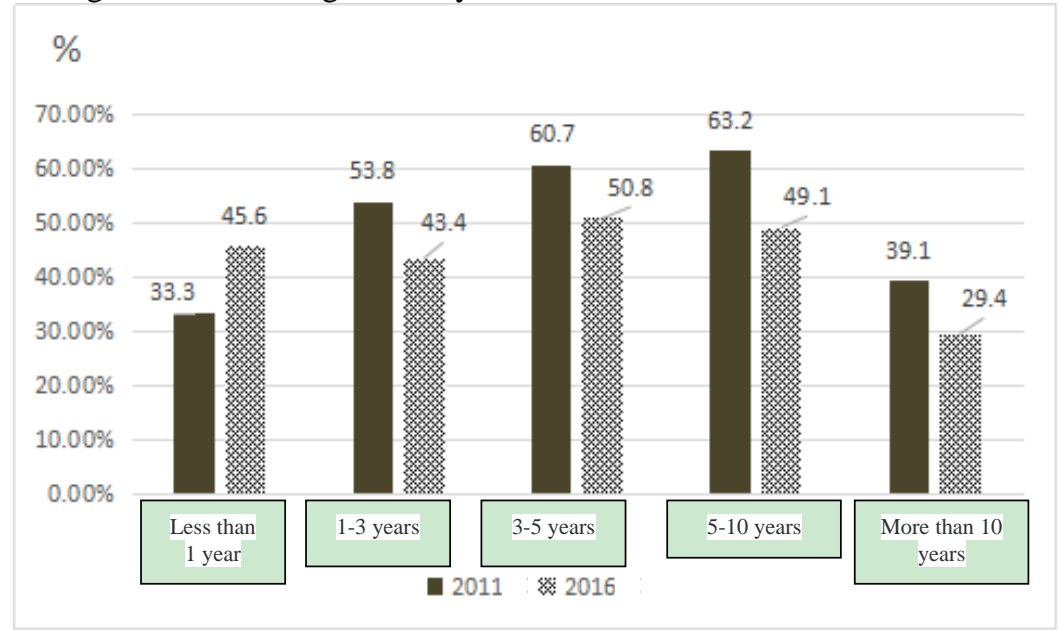

Fig. 3. Analysis on the importance of quality consciousness of higher vocational students in different working years.

According to further study in 2011, with the increase in length of service, the respondents attached importance to quality awareness. And it was a normal distribution. In "Fig. 3 ", with the increase in length of service, the importance of quality awareness also increased. 5-10 years of work was the peak. And then, the working age decreased. It shows that employees who have certain working experience pay more attention to quality awareness. However, those who have more than 10 years of working experience have reached the level of proficiency in the work. There is not too much demand for quality awareness. However, the data of 2016 shows that there is not much difference in quality awareness between employers and employees of all ages. On the one hand, in the past five years, employers have increased their 
awareness of quality in new recruits. And then, their knowledge of staff of all ages tends to be consistent. On the other hand, enterprises pay attention to the development of customers to meet growing demand. However, it doesn't make excessive demands for quality awareness.

4) Employer units reduce the awareness of the market operation for higher vocational students: Each professional post demands a lower awareness of the market operation of higher vocational students.

The data shows that there is a reduction in awareness of market operations for different professional posts such as running from $55.3 \%$ to $48.4 \%$, marketing (from $55.6 \%$ to $53.2 \%$ ) and sports (from $58.9 \%$ to $40.2 \%$ ). The employers reduce the flexibility of higher vocational students. And they hope that vocational students can adapt to the needs of job specifications.

a) Urban state-owned units, governments and public institutions reduce market awareness for higher vocational students: And we could make the interactive classification analysis of nature and market operation consciousness ( $\mathrm{p}=0$. $252>0.050)$. The importance of market operation consciousness of "urban state-owned unit" $(p=0.004<0.05)$ and "government organization or institution" ( $\mathrm{p}=0.003<$ 0.05 ) was significantly reduced from $69.2 \%$ to $27.3 \%$, and from $62.5 \%$ to $23.5 \%$, respectively. It shows that the awareness of government and state-owned units is strengthened, which is related to the gradual standardization of macro-legal economic policy in China.

It can be seen that the gradual perfection of Chinese law and the strengthening of rational understanding of the law of talent training are the important reasons for the lower attention to the market operation consciousness of vocational college students.

5) There is little change in the emphasis on qualifications by professional posts: The data shows that the employer's attention to the qualification certificate is not significant. Specifically, the professional marketing posts pay little attention to professional qualification certificate $(\mathrm{P}=0.003<0.050$, from $61.5 \%$ to $40.5 \%)$. The importance of professional marketing posts (from $31.6 \%$ to $40.9 \%$ ) and physical education posts (from $43.8 \%$ to $39.2 \%$ ) pay attention to professional qualification certificate. However, there was no significant change $(\mathrm{P}>0.05)$.

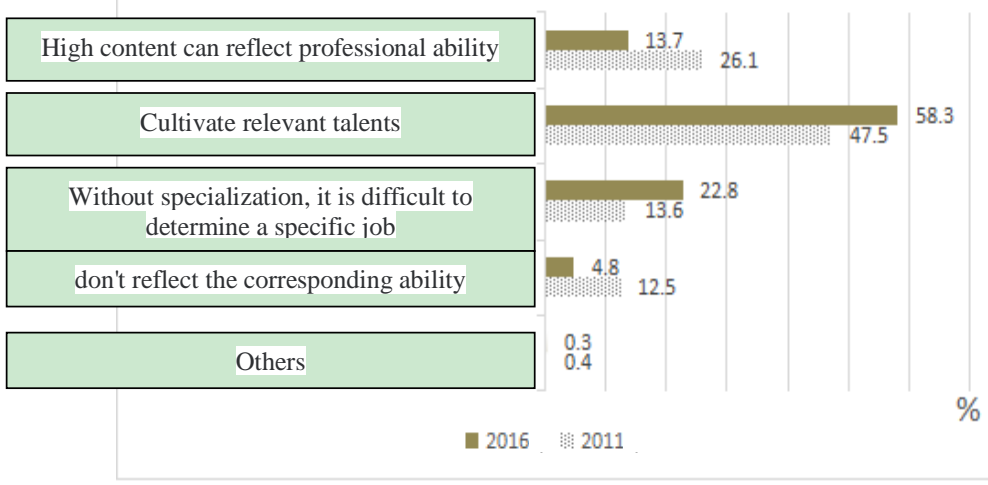

Fig. 4. Analysis on the change of employer's opinion on qualification certificate.

We should make further analysis of the employer's views on the vocational qualification certificate. As you can see in "Fig. 4", the employers believe that the perception of "people who can help us develop and select the right level of talent" has always accounted for the largest proportion $(47.5 \%$, $58.3 \%$ ). And there was a trend of growth. It would represent that more employers expected the certificate. The employers thought that "the high gold content would reflect the professional ability". And it decreased significantly, from $26.1 \%$ to $13.7 \%$. For the employers, "without pertinence, it is difficult to be competent for a specific job". It would increase from $13.6 \%$ to $22.8 \%$, indicating that the certificate did not play a due role. 
C. Changes in the Views of Employers on the Importance Attached to the Key Competencies of Vocational College Students

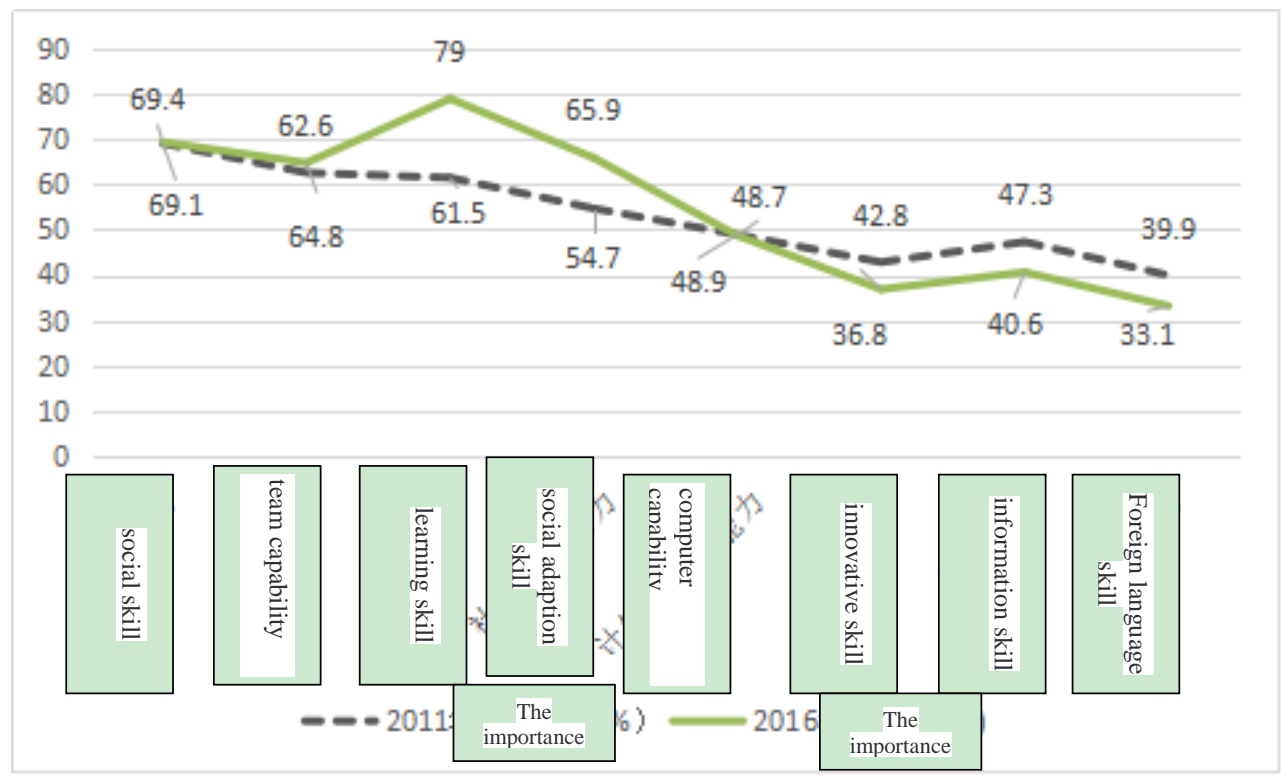

Fig. 5. Comparative Analysis of Employers' Perceptions on the Importance of Key Ability of Higher Vocational College Students.

As can be seen from the 2011 survey data in "Fig. 5", the most important key competence is communicative competence. The second is team ability. The third is learning ability, the fourth is social adaptation. Their values were $69.1 \%, 62.6 \%, 61.5 \%$ and $54.7 \%$. By 2016 , learning ability (79.0\%), communication ability $(69.4 \%)$ and social adaptation ability (65.9\%) were the top three key competencies. However, the order of emphasis was changed. The learning ability was the most important key competency. And communication ability was the second. The social adaptation ability was the third. However, other key competencies had no significant changes.

This paper makes a further analysis of the key capabilities of ranking in the first three items.

1) The importance of professional posts to the learning ability of students in higher vocational schools is improved significantly: Employers pay more attention to higher vocational students' learning ability, from $61.5 \%$ to $79.0 \%$. Specifically, from 2011 to 2016 , the professional posts have significantly increased the importance of learning ability of higher vocational students ( $\mathrm{p}$ value of $0.005,0.049$ and 0.000 are less than 0.050 ). The administrative management increased from $63.2 \%$ to $78.6 \%$. The marketing increases from $67 \%$ to $79.3 \%$. And the sports increase from $52.1 \%$ to $79.4 \%$. Therefore, the important role of learning ability has been highly valued by various professional posts.

Through the interaction and classification analysis of unit nature and learning ability, we can find that the importance of learning ability of companies and private-owned businesses and individual industrial and commercial households increase significantly from 2011 to 2016 (P = $0.000<0.050, \mathrm{P}=0.001<0.050$ ), from $49.4 \%$ to $85.8 \%$, from $69.5 \%$ to $86.7 \%$, respectively. Companies and private, self-employed units are the largest number of occupants of the group. Their demand for the learning ability of professional talents represents the direction of social demand. It fully shows the importance of learning ability.

2) Different professional posts have different emphasis on the communicative competence of vocational college students: From 2011 to 2016, there were no significant changes in the importance of communicative competence in managerial posts $(\mathrm{p}=0.053>0.050)$ and sports posts $(\mathrm{p}=0$. $725>0.050)$. However, the importance of communicative competence in marketing posts $(\mathrm{p}=0.043<0.05)$ increased significantly from $61.5 \%$ to $74.8 \%$, which was related to the nature of marketing posts.

3) The importance of professional posts to the social adaptability of vocational college students is significantly improved: The data shows that from 2011 to 2016, employers' emphasis on social adaptation increased significantly $(\mathrm{p}=0.004<0.050$ ), from $54.7 \%$ to $65.9 \%$. Specifically, from 2011 to 2016 , the professional posts have increased the importance of social adaptability, from $56.1 \%$ to $71.1 \%$ (administrative management), $64.8 \%$ to $67.6 \%$ (marketing) and $39.7 \%$ to $55.9 \%$ (sports). It indicates that the important role of social adaptability has been highly valued by the professional posts.

\section{The Employer's Suggestion on the Training of Higher Vocational Students}

We could find that the recommendations of the employer in 2011 are to strengthen the training of students' professional knowledge, to enhance professional skills and communication skills. The recommendations in 2016 are to 
enhance professional skills and communication skills and the accumulation of basic knowledge.

\section{CONCLUSION AND DISCUSSION}

\section{A. Management Majors always Have the Greatest Demand} for Vocational Ability of Vocational College Students

There were significant differences in the occupational ability needs of different vocational positions for higher vocational students in 2011. However, this difference was not significant in 2016. In general, we still maintain the top spot among all professional qualities. And the opinions of various professional posts tend to be in line. The industry has specialized. For different professional high-vocational students, to learn professional skills is the basic requirements of their own work.

\section{B. The Employer's Demand for Higher Vocational Students' Knowledge Quality Has Increased Significantly}

With the development of society, both the importance of basic knowledge and professional knowledge is significantly increased. Knowledge is the basis of the sustainable development of professional talents. Employers pay more attention to the quality of knowledge, which shows that employers have strategic vision. At the same time, the employer's higher recruitment in the future will pay more attention to the professional knowledge. In this way, the hypothesis of "reducing the demand for knowledge" is falsified.

\section{The Employers' Requirements on the Market Operation Consciousness and Quality Consciousness of the Vocational Students Are Significantly Reduced, and They still Need to Attach Importance to It}

The survey on the quality demand of fresh graduates shows that the employers' requirements on the market operation consciousness and quality consciousness of new graduates are significantly reduced. It may be the requirements for new graduates to enter the field of work. And we hope that new graduates can adapt to the job standards as soon as possible. The market operation consciousness means that the students understand the product marketing process. They can carry on the market research. Also, they can carry on the production according to the market need (Zhang Guohong, 2006). Therefore, we should not ignore the training of students' market operation consciousness. And we should adhere to the unity of rules and flexibility. At the same time, the quality of products or services is the lifeline of enterprises. The vocational students should firmly establish the awareness of "quality first". In the future, we should control the quality (Zhang Guohong, 2006). Therefore, combined with the opinions of experts, we should also attach importance to the quality awareness of vocational students; lay the foundation for the future development of vocational students.

\section{The Attention Paid by the Employer to the Certificate of Qualifications Has Not Been Reduced}

In accordance with the vocational skills standards or qualifications established by the State, objective, fair and scientific evaluation and appraisal of the skill level or vocational qualifications of workers are carried out through the appraisal and appraisal institutions identified by the Government. And the corresponding national vocational qualifications certificate is awarded to those who are qualified (Yang Shunqi, 2014). The certificate of qualification has not played its due role. In recent years, the importance of the employer to the certificate of qualification is not significantly different. The employer is still full of expectations. And the hypothesis of "reducing the importance of the certificate of qualification" was falsified. To link the post standards, industry standards and certificate evaluation standards is the next step in the direction.

\section{E. More Attention Should Be Paid to Learning Ability.}

There Are Professional Differences in the Importance of Communication Ability, and the Importance of Social Adaptation Ability Should Be Improved Significantly

Learning ability is the most important key ability for management majors. Learning ability is the comprehensive quality of individual learners in the learning process. The correct control of the actual ability and proficiency of learning activities is an effective way to meet the learning needs and complete the learning tasks through various channels. It is a positive force that influences individual development and academic achievements (Li Zhihe, Wang Ling, 2013). Employers pay more attention to the learning ability, which shows that the ability of sustainable development of talents is highly valued. Communicative competence is the foundation of establishing good interpersonal relationship. Therefore, special attention should be paid to the professional posts which have close contact with people. The ability to adapt to society can enable us to make the development and progress in society. It is the key to the development in the future. The professional posts should pay more attention to the ability to adapt to the society.

\section{CONCLUSION}

\section{A. The Schools}

We should increase the width and depth of the knowledge of vocational college student, and give the students the chance to improve their academic credentials We should investigate the employer, determine the basic knowledge and professional knowledge courses required for future professional positions, and contact the relevant undergraduate colleges to create opportunities for higher vocational students to upgrade their academic credentials.

It should provide more social practice activities for higher vocational students, such as opening up more professional practice bases, holding more various activities, and encouraging higher vocational students to participate in 
teacher's topic. And then, it could improve their professional skills, communicative ability and social adaptability.

We should take the learning ability as the important content of vocational quality training. Guided by special courses, the students in higher vocational colleges can have correct understanding in the aspects of learning ideas, learning methods and learning habits.

It should examine and verify the contents of the professional qualification certificate. And we should ensure that the professional qualification certificate is consistent with the standard of post, industry and enterprise. And then, it would provide guarantee for the smooth employment of vocational students.

\section{B. The Teachers}

The teachers should actively contact with the society, and improve their comprehensive quality. Teachers should take the initiative to communicate with the employing unit experts, improve their communicative ability, adaptive ability and learning ability. They could teach the students in the words and deeds.

The course teaching should be closely related to the post demand. The quality consciousness and the market operation consciousness will be brought into each curriculum training goal. The students should have strict earnest learning attitude and the ability to use the knowledge.

The students should check the vocational qualification certificate for vocational students. The combination of post, enterprise, industry standards and teaching objectives of professional courses is to enhance vocational students' professional skills. Also, it could help vocational students to select the professional qualifications needed for professional posts.

It should strengthen the cultivation of students' professional knowledge, attach importance to the combination of class and competition, enhance their professional skills in the application of professional knowledge, and enhance their communicative ability in practice.

\section{The Students}

The students should participate in practice activities; improve their professional skills, communication skills and social adaptation.

The students should take the teachers' learning tasks seriously, and improve their learning ability and quality consciousness in the specific course.

The students should actively understand the needs of the post and choose to obtain the professional qualification certificate suitable for yourself. The students should know more about the needs of different jobs. They should determine the employment goals and obtain the relevant professional qualification certificate as soon as possible.

The students should accumulate and apply professional knowledge. In practice, the students should enhance professional skills and communication skills, and strengthen the accumulation of basic knowledge.

\section{REFERENCES}

[1] Hu Xueqin, Lu Wanjun. Reasons and countermeasures of insufficient employment in China's economic growth [J]. The Economic Crisis, 2009, (06): 20-23.

[2] Wang Xiuyan, Qiao Limin. Empirical research on cultivation of skills and key competence in vocational education [J]. Chinese Vocational and Technical Education, 2011, (30): 52-55.

[3] Zhang Guohong. Professional quality [M]. Beijing: Economic Management Press, 2006

[4] Liu Yaling, Lu Shuzhen, Li Bin. An empirical study on the disparity between the quality of higher vocational students and the competency of business talents [J]. Human Resource Management, 2011, (10): 8890.

[5] Liu Lanming. Exploration of vocational literacy education - on "key competencies" of vocational education [J]. China Higher Education Research, 2011, (08): 86-87.

[6] Li Tiren, Li Jia. On the relationship between the training of vocational ability and quality education [J]. Vocational Education Research, 2013, (04): 13-15.

[7] Zhang Ting, Zeng Lingze. Analysis on cultivating key competence of administration students in higher vocational education [J]. Gansu Science and Technology, 2014, (19): 71-74.

[8] Li Chunyan. Analysis of definition and development of key capabilities of students in higher vocational colleges [J]. Journal of Jiamusi Vocational College, 2015, (01): 4-5.

[9] Liu Yaling, He Yan. A comparative study on the quality demands of employers for students in higher vocational colleges with different specialities - A case study of professional management, marketing, sports service and management [J]. Journal of Chifeng University (Natural Science Edition), 2016, (02): 215-219.

[10] Yang Shunqi. The development and trend of vocational and technical qualification certificate [J]. The Science Education Article Collects (the last ten-day of a month), 2014, (09): 213-214.

[11] Li Zhihe, Wang Ling. A study on the construction of evaluation system for learning ability of vocational students in China [J]. Journal of Shanxi Normal University (Social Science Edition), 2013, (02): $151-156$ 